SANDIA REPORT

SAND2007-6810

Unlimited Release

Printed November 2007

\title{
Aluminum Alloys for Satellite Boxes: Engineering Guidelines for Obtaining Adequate Strength While Minimizing Residual Stresses and Machining Distortion
}

Mandy S. Younger and Kenneth H. Eckelmeyer

Prepared by

Sandia National Laboratories

Albuquerque, New Mexico 87185 and Livermore, California 94550

Sandia is a multiprogram laboratory operated by Sandia Corporation, a Lockheed Martin Company, for the United States Department of Energy's National Nuclear Security Administration under Contract DE-AC04-94AL85000.

Approved for public release; further dissemination unlimited. 
Issued by Sandia National Laboratories, operated for the United States Department of Energy by Sandia Corporation.

NOTICE: This report was prepared as an account of work sponsored by an agency of the United States Government. Neither the United States Government, nor any agency thereof, nor any of their employees, nor any of their contractors, subcontractors, or their employees, make any warranty, express or implied, or assume any legal liability or responsibility for the accuracy, completeness, or usefulness of any information, apparatus, product, or process disclosed, or represent that its use would not infringe privately owned rights. Reference herein to any specific commercial product, process, or service by trade name, trademark, manufacturer, or otherwise, does not necessarily constitute or imply its endorsement, recommendation, or favoring by the United States Government, any agency thereof, or any of their contractors or subcontractors. The views and opinions expressed herein do not necessarily state or reflect those of the United States Government, any agency thereof, or any of their contractors.

Printed in the United States of America. This report has been reproduced directly from the best available copy.

Available to DOE and DOE contractors from

U.S. Department of Energy

Office of Scientific and Technical Information

P.O. Box 62

Oak Ridge, TN 37831

Telephone: $\quad$ (865) 576-8401

Facsimile: (865) 576-5728

E-Mail:_ reports@adonis.osti.gov

Online ordering: http://www.osti.gov/bridge

Available to the public from

U.S. Department of Commerce

National Technical Information Service

5285 Port Royal Rd.

Springfield, VA 22161

Telephone: $\quad$ (800) 553-6847

Facsimile: $\quad$ (703) 605-6900

E-Mail: $\quad$ orders@ntis.fedworld.gov

Online order: $\quad$ http://www.ntis.gov/help/ordermethods.asp?loc=7-4-0\#online

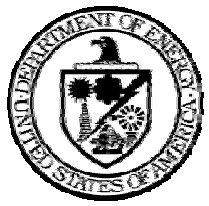


SAND2007-6810

Unlimited Release

Printed November 2007

\title{
Aluminum Alloys for Satellite Boxes: Engineering Guidelines for Obtaining Adequate Strength While Minimizing Residual Stresses and Machining Distortion
}

\author{
Mandy S. Younger and Kenneth H. Eckelmeyer \\ Satellite Mechanical Design and Materials Characterization \\ Sandia National Laboratories \\ P.O. Box 5800 \\ Albuquerque, New Mexico 87185-0968
}

\begin{abstract}
This report provides strategies for minimizing machining distortion in future designs of aluminum alloy satellite boxes, based in part on key findings from this investigation. The report outlines types of aluminum alloys and how they are heat treated, how residual stresses develop during heat treatment of age hardening alloys, ways residual stresses can be minimized, and the design of machining approaches to minimize distortion in parts that contain residual stresses. Specific recommendations are made regarding alloy selection, heat treatment, stress relieving, and machining procedures for boxes requiring various strength levels with emphasis on 6061 and 7075 aluminum alloys.
\end{abstract}




\section{ACKNOWLEDGMENTS}

Many colleagues participated in portions of this study. The authors appreciate the efforts of Gary Gallegos and Don Green, who conducted the heat treatment and quenching experiments; Jack Stephens, Roger Castillo, and Joe Nekoranec, who machined the test samples and measured subsequent distortions; and Tom Crenshaw and John Laing, who conducted the mechanical tests. We also appreciate the comments and helpful reviews of Jim VanDenAvyle, Don Susan, and Curtis Gibson. 


\section{CONTENTS}

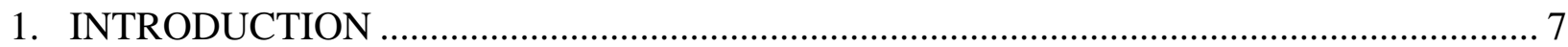

2. ALUMINUM ALLOYS, HEAT TREATMENT, AND STRENGTH................................. 7

3. DEVELOPMENT OF RESIDUAL STRESSES DURING QUENCHING ........................ 10

4. AVOIDING EXCESSIVELY HIGH RESIDUAL STRESSES ........................................ 12

4.1 Minimizing Quench-Induced Residual Stress Development During Quenching ......... 12

4.2 Reducing Residual Stresses After They Are Present (Following Quenching) ............. 14

4.2.1 Thermal Stress Relieving...................................................................... 14

4.2.2 Mechanical Stress Relieving................................................................ 15

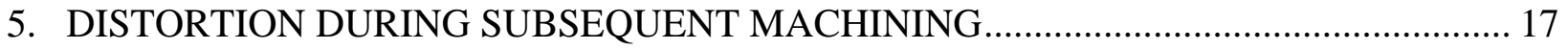

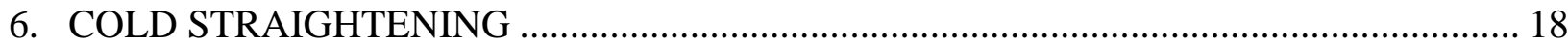

7. PRACTICAL GUIDELINES FOR DESIGNING AND PRODUCING

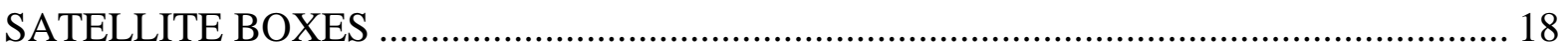

7.1 Boxes With Very Low Strength Requirements .................................................. 19

7.2 Boxes With Intermediate Strength Requirements................................................... 19

7.3 Boxes Requiring High Strength ........................................................................ 19

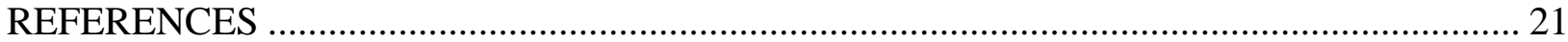

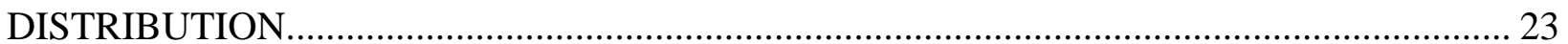




\section{FIGURES}

Figure 1. Effect of Plate Thickness on Yield Strength and Ultimate Tensile Strength of

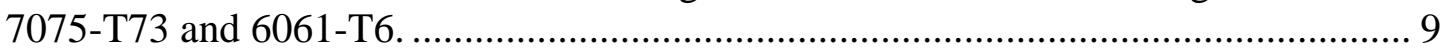

Figure 2. Typical Pattern of Balanced Residual Stresses Through A Quenched Plate.............. 10

Figure 3. Effect of Thickness on Maximum Residual Stress in As-Quenched 7075 and

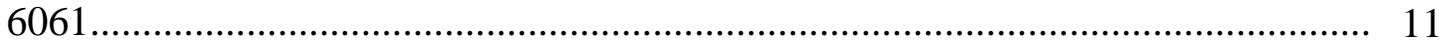

Figure 4. Effect of Quench Water Temperature on Peak Residual Stress in 1-Inch-Thick

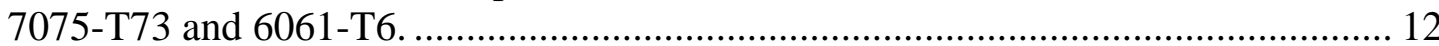

Figure 5. Effect of Quench Water Temperature on Yield and Ultimate Tensile Strength in 1-Inch-Thick 7075-T73 and 6061-T6.

Figure 6. Effect of Overaging Temperature on Peak Residual Stresses in 1-Inch-Thick 7075

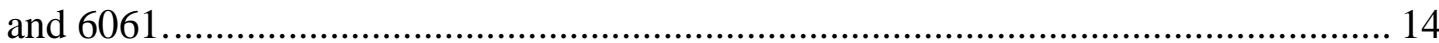

Figure 7. Effect of Overaging temperature on Yield Strength and Ultimate Tensile Strength in 1-Inch-Thick 7075 and 6061

Figure 8. How Compressive Stress Leveling Reduces Residual Stresses.................................... 16

Figure 9. Electrically Discharge Machined Wire Cut Along the Centerplane (7075-T6). ......... 17 


\section{INTRODUCTION}

Distortion during machining has been a recurring problem in the production of high strength aluminum alloy box frames for Sandia National Laboratories satellite applications. The distortion problem peaked during a recent yearlong effort to manufacture a particularly large and complex box. Excessive distortion resulted in nearly $100 \%$ of the machined boxes failing to meet dimensional tolerances. As a result, a metallurgical investigation was conducted to understand and overcome this distortion problem. This report provides strategies for minimizing machining distortion in future designs, based in part on key findings from this investigation. The results of specific experiments conducted during this investigation are presented and discussed in much greater detail in a companion report. ${ }^{1}$

The current report outlines:

- types of aluminum alloys and how they are heat treated,

- how residual stresses develop during heat treatment of age hardening alloys,

- various ways in which residual stresses can be minimized, and

- how machining approaches can be designed to minimize distortion in parts that contain residual stresses.

Specific recommendations are then made in the context of the above principles regarding alloy selection, heat treatment, stress relieving, and machining procedures for boxes requiring various strength levels. Particular emphasis is placed on 6061 and 7075 aluminum alloys, as these have been used in numerous satellite box applications.

\section{ALUMINUM ALLOYS, HEAT TREATMENT, AND STRENGTH}

There are two basic categories of wrought aluminum alloys:

- Non-heat treatable (strengthened only by various combinations of alloying and cold work), and

- Age hardenable (strengthened by solution heat treatment, quenching, and subsequent age hardening).

Non-heat treatable alloys include various grades of commercially pure aluminum (series 1000), Al-Mn alloys with up to $1.5 \% \mathrm{Mn}$ (series 3000 alloys), and Al-Mg alloys with up to 5\% Mg (series 5000 alloys). These materials are strengthened by the solid solution effects of the alloying elements, and in some cases by cold working. Cold working is commonly employed to strengthen thin regular sections, such as sheets. However, cold working would be both impractical and undesirable for thick sections or irregular parts, such as satellite boxes. Yield strengths in the annealed condition range from $\sim 5 \mathrm{ksi}$ for 1100 aluminum (commercial purity unalloyed Al) to 15 ksi for thick plates of various 5000-series alloys. Similar strength levels are also available with various aluminum casting alloys in the as-cast or annealed condition, but with considerably lower ductility. In addition, aluminum castings frequently contain defects, making them inappropriate for applications requiring very high reliability. The primary advantage of using annealed 5000-series alloys for satellite box applications would be that they contain virtually no residual stress provided they have been completely annealed; hence they should exhibit little to no distortion during machining. Their primary disadvantage is that they are not very strong, so they could only be used in boxes where strength requirements were minimal. 
Age-hardenable alloys are typically used where higher strengths are needed, and where it is impractical to accomplish the required amount of strengthening by cold working. There are three major classes of wrought age-hardenable aluminum alloys:

- 2000 series alloys contain mostly copper additions and are strengthened by the formation of Al-Cu intermetallic compound precipitates. These are the earliest/oldest age hardening $\mathrm{Al}$ alloys, reaching peak yield strengths of $\sim 60 \mathrm{ksi}$.

- 7000 series alloys contain zinc, magnesium, and copper additions and are strengthened by the formation of Mg-Zn intermetallic compound precipitates. These are the highest strength aluminum alloys, reaching peak yield strengths as high as $73 \mathrm{ksi}$. 7075 is the most widely used 7000-series alloy.

- 6000 series alloys contain magnesium and silicon additions and are strengthened by the formation of Mg-Si intermetallic compound precipitates. These are less strong than most 2000 and 7000 series alloys, exhibiting peak yield strengths of only 40 ksi. However, they are easier to heat treat, exhibit better fracture toughness and resistance to stress corrosion cracking, and are less prone to machining distortion (as will be discussed in more detail in later sections). 6061 is the most widely used 6000-series alloy.

Age-hardenable aluminum alloys, including 6061 and 7075, are heat treated in a three-step process:

1) Solution heat treatment (typically in the vicinity of 900 to $1000^{\circ} \mathrm{F}$ ) dissolves the alloying additions into solid solution in the aluminum. The alloying elements have very limited solubilities in $\mathrm{Al}$ at room temperature, but their solubilities increase substantially with increasing temperature. During solution heat treatment the alloying additions dissolve in the $\mathrm{Al}$, resulting in a crystal structure similar to that of pure $\mathrm{Al}$, but with atoms of the alloying elements substituted for some of the $\mathrm{Al}$ atoms.

2) At the end of the solution treatment the material is rapidly cooled (quenched) to room temperature, thus retaining a supersaturated solution at room temperature. Effective quenching is essential for obtaining supersaturation, which is a prerequisite for subsequent age hardening. Unfortunately, internal stresses are generated during the quenching process. These residual stresses are the root cause of the distortion that occurs during subsequent machining, as will be more fully described in Section 5.0.

3) Age hardening (typically in the vicinity of 250 to $350^{\circ} \mathrm{F}$ ) allows controlled precipitation to occur from the supersaturated solid solution. Due to the limited rates of diffusion at these relatively low temperatures, the precipitates are very fine and closely spaced, thus producing the desired increase in the strength of the material. The T6 aging treatment provides a combination of temperature and time that results in peak strength. T73 designates a slightly overaged condition that is often used with 7075 - a modest sacrifice in strength is made in order to gain increased fracture toughness and dramatically increased resistance to stress corrosion cracking.

As mentioned above, achieving "handbook strength values” during aging presupposes that the material was adequately quenched following solution heat treatment to retain a fully supersaturated solution. If quench rates are too slow, excessive diffusion of the alloying atoms can occur during the quench. This results in the formation of coarse precipitates that are relatively ineffective in strengthening. The degree of supersaturation is reduced, resulting in less- 
than-normal increases in hardness and strength during subsequent age hardening. In other words, material that has been "subcritically quenched" will not age harden to "full handbook strength."

Quench effectiveness generally depends on the thickness of the material, the quench medium (typically room temperature water), and alloy composition - some alloys are much more sensitive to quench rate than others. 6061 is relatively insensitive to quench rate, so it can be heat treated in thicknesses up to 12 inches with only a modest decrease in strength. 7075 is much more quench rate sensitive - 12-inch-thick sections are only about half as strong as thin sheet and plate. The effect of thickness on the strengths of 7075-T73 and 6061-T6 are shown in Figure 1.

Additional detail on various aluminum alloys, heat treatments, and properties can be found in References 2-4.

Figure 1 shows the effect of plate thickness on yield strength and ultimate tensile strength of 7075-T73 and 6061-T6. Lines represent predictions based on extrapolation of published cooling rate vs. thickness data, combined with published strength vs. cooling rate data. ${ }^{3}$ Points indicate strength values measured in this investigation. ${ }^{1}$

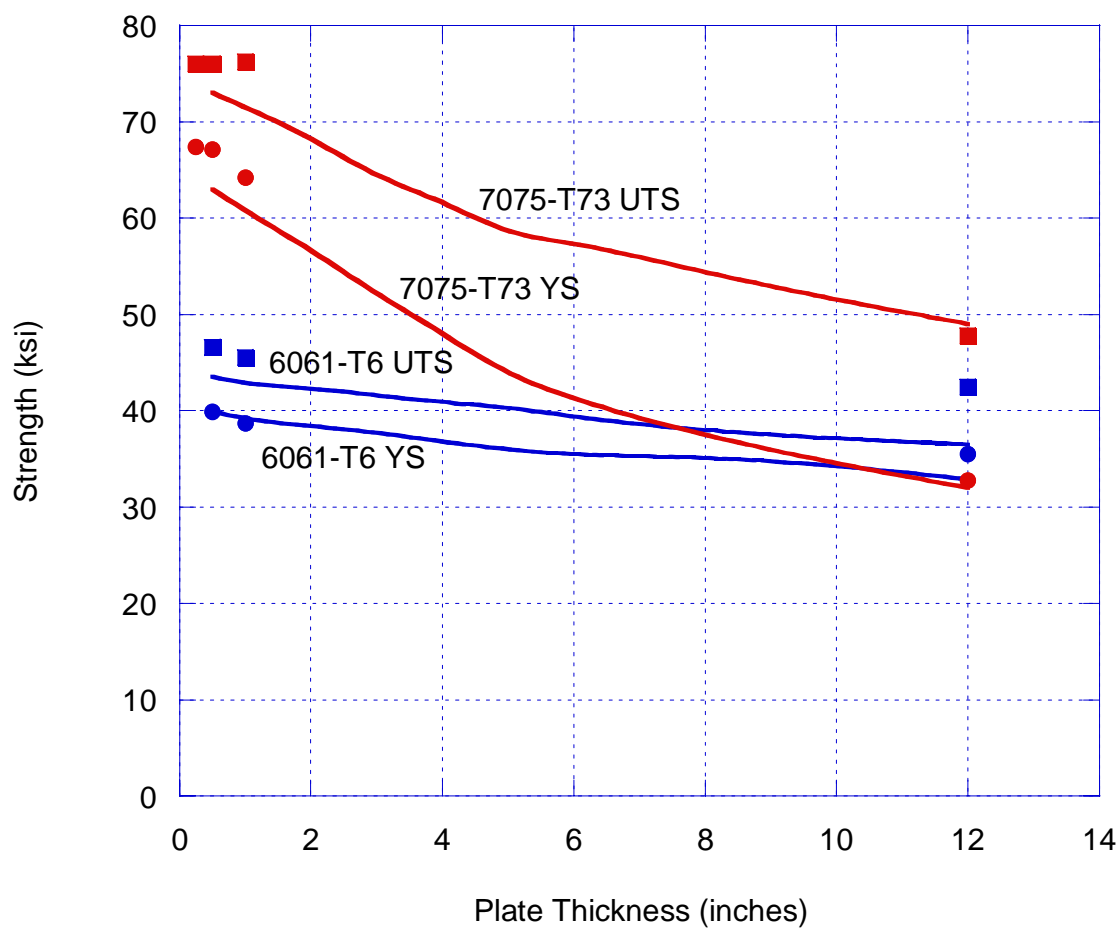

Figure 1. Effect of Plate Thickness on Yield Strength and Ultimate Tensile Strength of 7075-T73 and 6061-T6. 


\section{DEVELOPMENT OF RESIDUAL STRESSES DURING QUENCHING}

Residual stresses develop because of non-uniform cooling and the associated contractions that occur during the quench. When relatively thick parts are immersed in the quench bath the surfaces cool first and thus contract more rapidly than the interior. At this time (early in the quench) the interior provides little resistance to the contraction of the surfaces because the interior is still hot and soft - the soft interior simply plastically deforms to accommodate the contraction of the rapidly cooling surface. Later in the quench, however, when the interior cools, its contraction is resisted by the now cold and relatively strong near-surface material. As a result, tensile stresses develop in the interior - the material there wants to contract, but cannot. These tensile interior stresses are balanced by compressive stresses that develop near the surface. A symmetric pattern of residual stress develops with maximum compression on each surface and maximum tension along the centerline. This is illustrated in Figure 2.

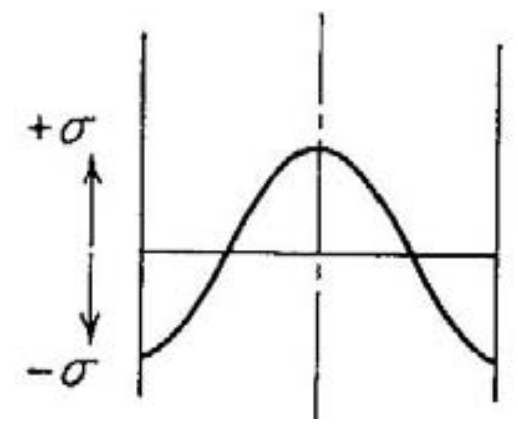

Figure 2. Typical Pattern of Balanced Residual Stresses Through A Quenched Plate.

Figure 2 shows a typical pattern of balanced residual stresses through the thickness of a quenched plate. Maximum compressive (negative) stresses exist at each surface, and maximum tensile (positive) stresses exist at the centerplane.

The magnitude of the peak compressive and tensile residual stresses depends on the severity of the quench, the thickness of the plate, and in some cases the yield strength of the material in the as-quenched condition. Typically, residual stresses are quite low in thin sheets and plates, increase with increasing plate thickness, and reach as-quenched yield strength in thick plates (Figure 3$)^{1}$. This occurs because quench uniformity decreases with increasing thickness, i.e., larger surface-to-center temperature differentials exist during quenching of thick plates than thin ones. Residual stress magnitudes in thin to moderately thick plates are controlled by the extent of the surface-to-center temperature differentials during quenching, thus they increase with increasing plate thickness. At some point the plate thickness becomes high enough that the peak residual stress magnitude equals the material yield strength (i.e., the yield strength in the asquenched condition - this is considerably lower than yield strength after age hardening). Thereafter (in thicker plates) the peak residual stress magnitude remains constant, as it is limited by as-quenched yield strength rather than by the thermal gradients during the quench. 


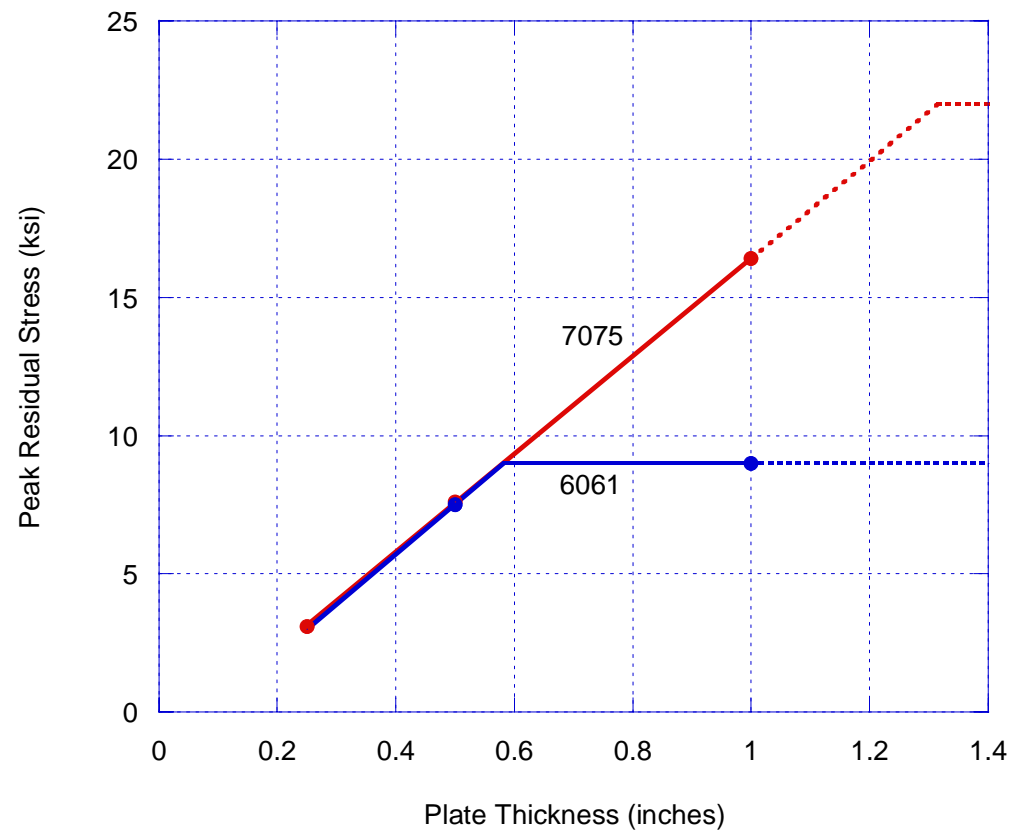

Figure 3. Effect of Thickness on Maximum Residual Stress in As-Quenched 7075 and 6061.

Figure 3 shows the effect of thickness on maximum residual stress in as-quenched 7075 and 6061. Residual stress increases with increasing thickness up to as-quenched yield strength. (Note that in thin sections the similar thermal properties of 7075 and 6061 result in identical residual stresses.) Beyond as-quenched yield strength ( 9 ksi for 6061 and $\sim 22$ ksi for 7075) residual stress is limited by the as-quenched yield strength of the material.

Measurements made during this investigation suggest that peak residual stresses equal to asquenched yield strength occur in 6061 plates thicker than 0.6 inch, and in 7075 plates thicker than 1.3 inch (when quenched in cold water), as shown in Figure 3. ${ }^{1}$ For the 10 - 12-inch-thick plates frequently used in making satellite boxes the peak quenching stresses are clearly limited by the as-quenched yield strength in both of these alloys. These yield-strength-limited residual stresses are considerably lower in thick plates of 6061 than in 7075 because 6061 has a much lower as-quenched yield strength than 7075 ( $\sim 9 \mathrm{ksi}$ for 6061, compared to $\sim 22 \mathrm{ksi}$ for 7075). As a result, considerably less distortion would be expected to occur during machining of boxes from thick plates of 6061 than from 7075 (all other things being equal - see the following sections). Beyond as-quenched yield strength ( 9 ksi for 6061 and $\sim 22 \mathrm{ksi}$ for 7075 ) residual stress is limited by the as-quenched yield strength of the material. ${ }^{1}$ 


\section{AVOIDING EXCESSIVELY HIGH RESIDUAL STRESSES}

There are two basic approaches to keeping residual stresses low:

- Minimizing the magnitude of stresses that develop during the quench, or

- Employing thermal or mechanical stress relieving processes after the quench to reduce the magnitudes of quench-induced residual stresses.

\subsection{Minimizing Quench-Induced Residual Stress Development During Quenching}

Minimizing stresses that form during the quench is approached differently depending on whether peak residual stress magnitude is controlled by the thermal gradient during quenching (thin sections), or is limited by the as-quenched yield strength of the material (thick sections).

In relatively thin material the key is to minimize the surface-to-center temperature differential during the quench. One way to accomplish this is by minimizing section thickness, i.e., not allowing excess overstock that will later be machined off. The effect of plate thickness on peak residual stress in as-quenched 7075 and 6061 is shown in Figure 3.

Another approach is to quench in warm water rather than in cold water. The effect of quench water temperature on peak residual stress in 7075-T73 and 6061-T6 is shown in Figure 4.

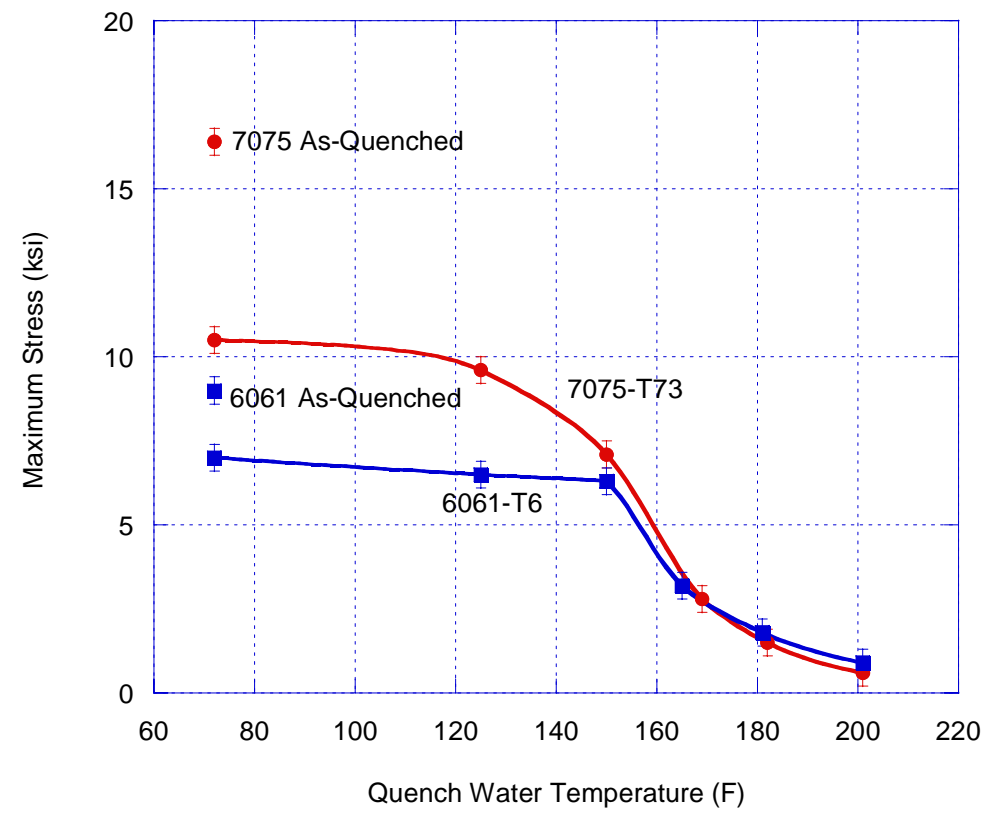

Figure 4. Effect of Quench Water Temperature on Peak Residual Stress in 1-Inch-Thick 7075-T73 and 6061-T6. 
This approach was investigated in detail in the current investigation. ${ }^{1}$ While quenching in warm water has the positive effect of reducing residual stresses, it can also result in subcritical quench rates, thus producing lower-than-handbook strengths. The degradation in strength that occurs with increasing quench water temperature is shown in Figure 5.

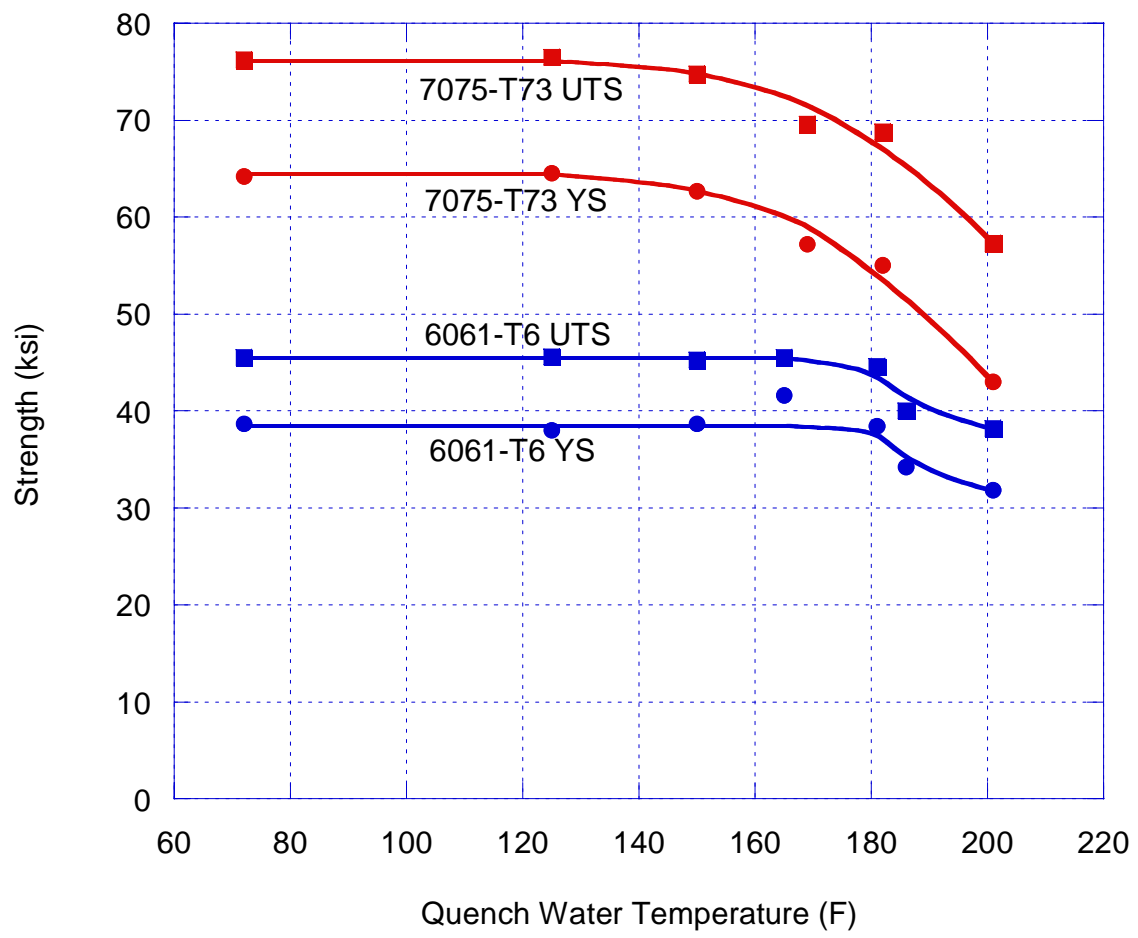

Figure 5. Effect of Quench Water Temperature on Yield and Ultimate Tensile Strength in 1-Inch-Thick 7075-T73 and 6061-T6.

The "trick" is to quench fast enough to permit adequate strength to be obtained during subsequent age hardening, but not faster - unnecessarily severe quenching results in higher residual stresses. A key finding of this investigation was that $~ 80 \%$ of residual stresses can be avoided when $0.5-1.0$-inch-thick sections of 7075 are quenched into water at 175 to $180^{\circ} \mathrm{F}$; however this results in only 15\% degradation in the strength obtained by aging to the T73 temper. This trade-off is discussed in additional detail in Reference 1 as well as in Section 7 of this report. The lower quench rate sensitivity of 6061 makes it even more amenable to warm water quenching, but mechanical stress relieving provides a simpler way to overcome residual stresses in 6061 plate, as will be discussed in Section 4.2.2.

In thick sections peak residual stress magnitude is limited by the material as-quenched yield strength (thicker than $\sim 1.3$ inch for 7075 or $\sim 0.6$ inch for 6061 when quenched into roomtemperature water). Because of this, peak stresses in relatively thick sections of as-quenched 6061 are $\sim 9 \mathrm{ksi}$, whereas those in as-quenched 7075 are $\sim 22 \mathrm{ksi}$. As a result, considerably less distortion should occur during machining of boxes from thick sections of 6061 than from 7075. 


\subsection{Reducing Residual Stresses After They Are Present (Following Quenching)}

Once residual stresses have been introduced during the quench they can be reduced by two types of post-quench processes: thermal or mechanical stress relieving.

\subsubsection{Thermal Stress Relieving}

Unfortunately, the options for thermal stress relieving are limited in age-hardened aluminum alloys. Relatively little stress relief occurs during standard age-hardening treatments, and heating to temperatures significantly above the normal aging temperature causes the material to overage and lose strength.

Aging of 6061 to the standard T6 condition relieves 22\% of the quench-induced residual stresses, aging of 7075 to the standard T6 condition relieves essentially none of the quenchinduced residual stresses, and overaging of 7075 to the standard T73 condition relieves 36\% of the quench-induced residual stresses. ${ }^{1}$ The commonly held notion that subsequent (post-aging) lower-temperature "stress relieving heat treatments" can further reduce residual stresses is unfounded and incorrect.

Additional stress relief can be accomplished by higher-temperature non-standard aging treatments, as shown in Figure 6.

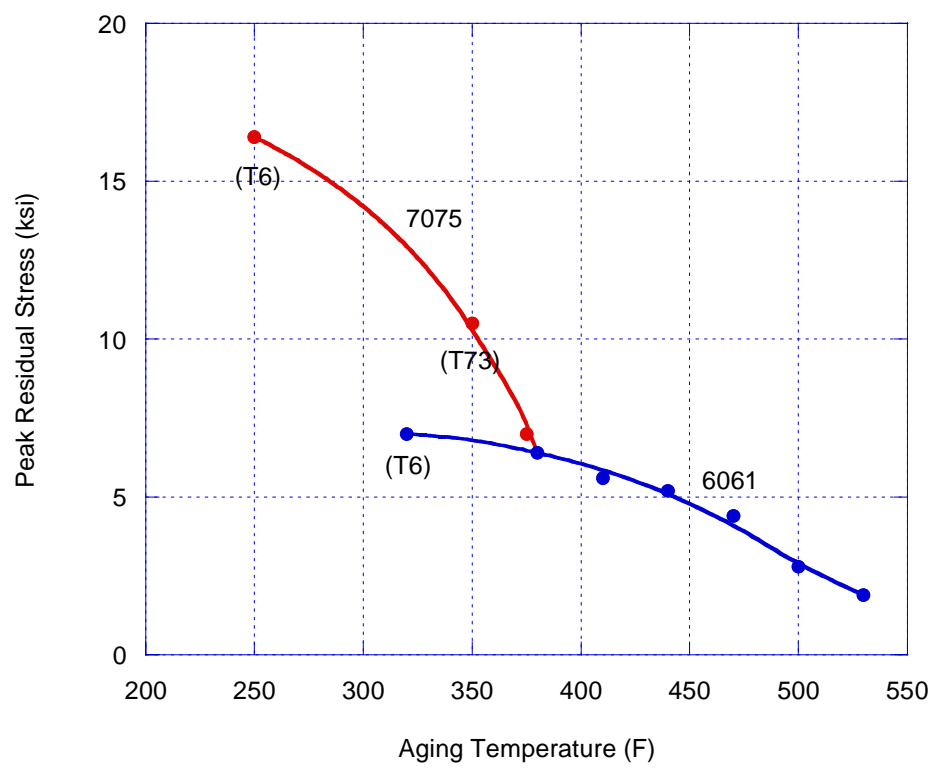

Figure 6. Effect of Overaging Temperature on Peak Residual Stresses in 1-Inch-Thick 7075 and 6061. 
However, significant reductions in strength occur, as shown in Figure 7.

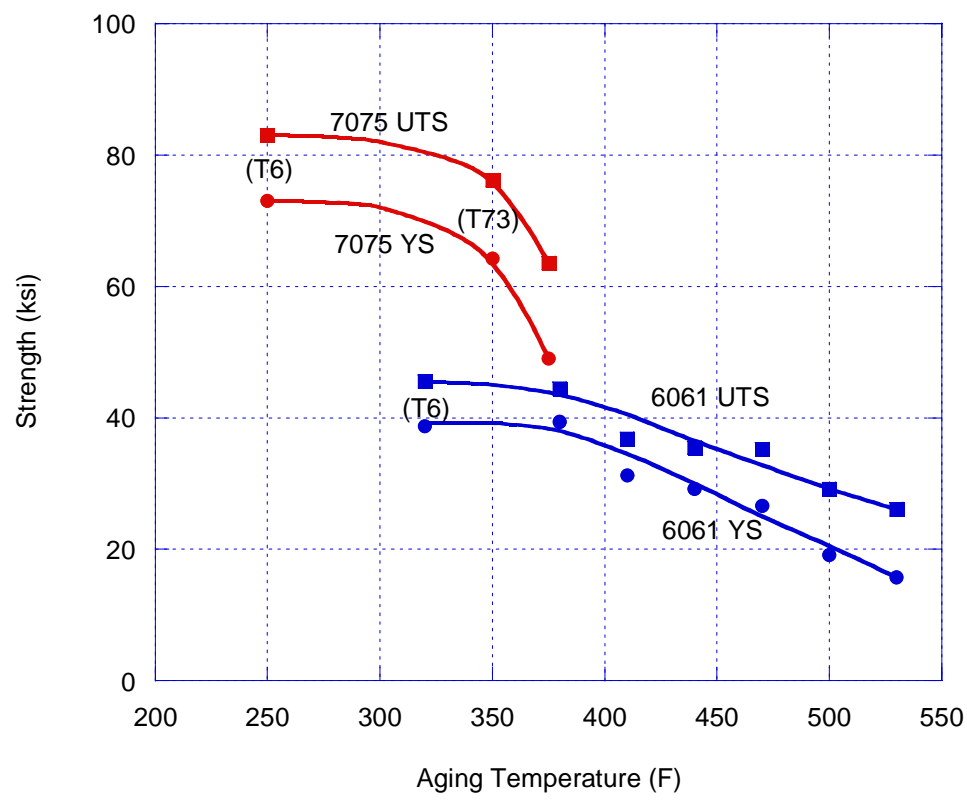

Figure 7. Effect of Overaging temperature on Yield Strength and Ultimate Tensile Strength in 1-Inch-Thick 7075 and 6061.

Comparison of Figures 6 and 7 with Figures 4 and 5 shows that much better combinations of high strength and low residual stress can be obtained by warm water quenching than by overaging. ${ }^{1}$

Figure 6 shows the effect of overaging temperature on peak residual stresses in 1-inch-thick 7075 and 6061. Points corresponding to the standard T6 and T73 aging treatments are noted. ${ }^{1}$ Figure 7 shows the effect of overaging temperature on yield strength and ultimate tensile strength in 1inch-thick 7075 and 6061. Points corresponding to the standard T6 and T73 aging treatments are noted. ${ }^{1}$

\subsubsection{Mechanical Stress Relieving}

A more practical way to reduce residual stresses is to mechanically stress level the material after quenching and before aging. Mechanical stress leveling consists of plastically deforming the material 2 to 3\% in either tension or compression, as illustrated in Figure 8.

Figure 8 shows the stress-strain curve illustrating how compressive stress leveling reduces residual stresses. Points A and B represent the initial peak residual stresses at the plate surface and center, respectively. During compressive stress leveling these move to positions A' and B' (separated by the same difference in strain, but now by a smaller difference in stress, as the compressive yield strength has been exceeded). These unload elastically to positions A" and B" following compressive stress leveling. 


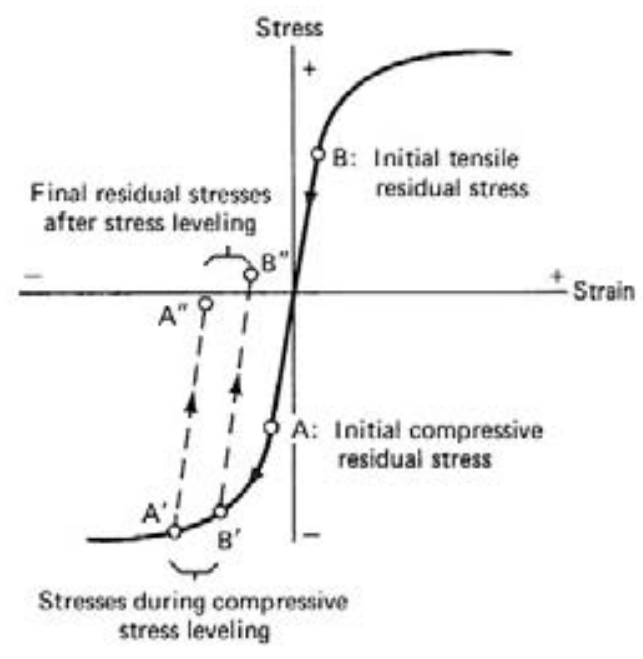

Figure 8. How Compressive Stress Leveling Reduces Residual Stresses.

Stress leveling in tension is commonly applied to sheet and plate. It typically reduces the residual stress magnitude by 80 to $95 \% .^{1}$ The temper designation of material that has been mechanically stress leveled in tension and subsequently age hardened to peak strength is T651. High-strength alloys, such as 7075, that have been mechanically stress leveled in tension and subsequently overaged beyond peak strength to improve toughness and resistance to stress corrosion cracking are designated T7351. Tensile "stretching" before aging is common mill practice with 6061 and 7075 sheet and plate to simultaneously reduce residual stresses and to straighten the material. However, the only way to guarantee that plates have been stress leveled in tension is to specify the T651 or T7351 condition - if only T6 or T73 are specified the material may or may not have been mechanically stress leveled.

Materials that have been mechanically stress leveled in compression and subsequently age hardened to peak strength are designated T652. High-strength alloys, such as 7075, that have been mechanically stress leveled in compression and then overaged beyond peak strength are designated T7352. Compressive stress leveling is most often used with less regularly shaped parts, such as forgings or, potentially, satellite boxes. It is typically less effective than stress leveling in tension, sometimes reducing the residual stress magnitude by as little as $50 \%{ }^{1}$

Since tensile stress leveling can be used only with parts of very uniform cross-section, it can only be applied to satellite boxes that are being machined from very thick plates. Quench rate considerations dictate that only 6061 can be adequately quenched in these very thick sections (see Figure 1). Recent experience with several designs confirms that very little distortion occurs during machining of satellite boxes from 12-inch-thick plates of 6061-T651. However, significantly more distortion occurred during machining of a box from a 6061-T6 forging that had not been mechanically stress leveled. It is clear that mechanical stress leveling must be specified in order to ensure dimensional stability during machining of 6061 satellite boxes.

If quench rate limitations dictate that the box be solution heat treated and quenched after the openings/pockets have been roughed in (as with 7075), the only stress leveling option would be to compressively stress level the rough machined and solution heat treated box by compressing it 
parallel to the axes of the roughed-in pockets before aging. This may not provide sufficient stress relief to avoid excessive machining distortion. Quenching in 175 to $180^{\circ} \mathrm{F}$ water appears to be a better approach with rough machined 7075 boxes. As described in Section 4.1, warm water quenching of 7075 followed by aging to the T73 condition results in an $\sim 80 \%$ reduction in residual stresses, while obtaining $\sim 55$ ksi yield strength -15 to 20 ksi higher than that of 6061-T6.

\section{DISTORTION DURING SUBSEQUENT MACHINING}

Distortion occurs during subsequent machining when material is removed asymmetrically with respect to the residual stress pattern. Taking the simplest case of a quenched plate with peak compressive stresses on each surface and peak tensile stress on the centerplane (as shown in Figure 2), consider what would happen if half the thickness was milled off - all from one side. The tensile and compressive stresses would no longer be symmetrically balanced - the original surface would be in compression (want to expand) and the opposing surface (formerly the centerplane) would be in tension (want to shrink). The desired expansion and shrinkage can, and does, occur by bending - the tensile surface becomes the concave side of the bend and the compressive surface becomes the convex side. The resulting bending deflections can be quite large. For example, Figure 9 is a photograph that shows the 0.085-inch mid-point deflections that occurred when a 10-inch-long plate of 1-inch-thick 7075-T6 was electrically discharge machined along its centerplane. Note the 0.85-inch mid-length distortions that occurred in each half when the plate was cut into two pieces.

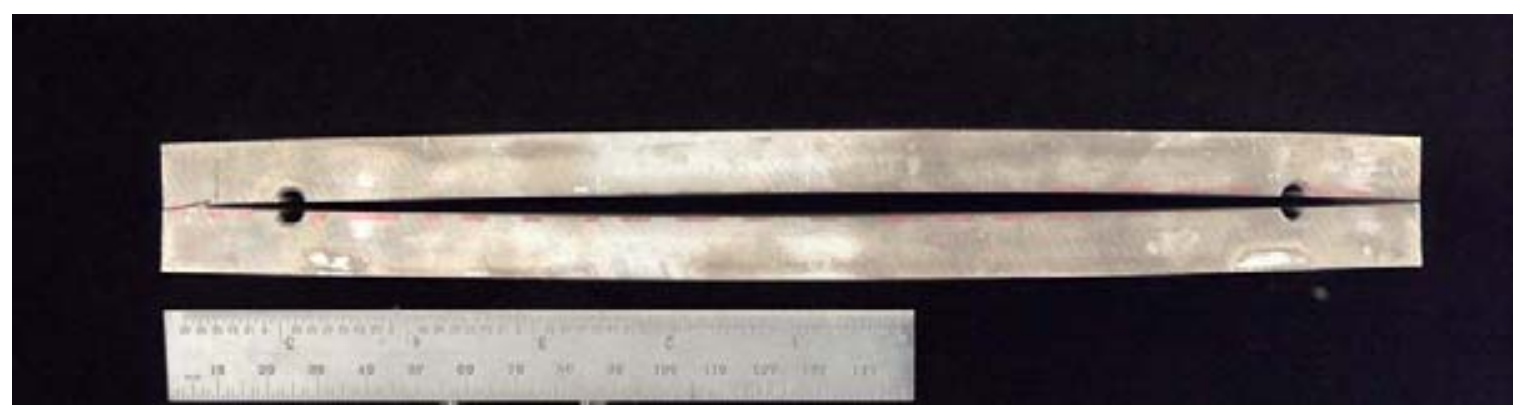

Figure 9. Electrically Discharge Machined Wire Cut Along the Centerplane (7075-T6).

As noted above, bending occurs when material is removed asymmetrically relative to the residual stress pattern. The residual stress pattern is, in turn, a reflection of thermal gradients in the material during the quench. Consider the simplest case of a semi-infinite plate in the $x-y$ plane with thickness in the z-direction. Heat extraction during the quench occurs one-dimensionally in the z-direction, producing in-plane residual stresses in the $\mathrm{x}$ - and $\mathrm{y}$-directions similar to those shown in Figure 2. Subsequent machining from one side to the mid-thickness of the plate will dramatically unbalance this residual stress pattern, and out-of-plane bending will result, the deflection occurring in the z-direction (the direction of heat extraction during the quench). On the other hand, saw cuts made perpendicular to the plane of the plate will not unbalance the residual stress pattern, so no distortion will result. 
A simple way to keep track of these somewhat confusing relationships is to think of it in terms of a bow and arrow. The arrow points in the direction of heat flow during quenching perpendicular to the plane of the plate. The string of the bow is in the plane of the plate perpendicular to the arrow. Distortion occurs when material is asymmetrically removed perpendicular to the arrow - parallel to the bow string. The distortion that results corresponds to bending of the bow, with the bending deflection being parallel to and in the direction of the arrow.

Consider now the more complex case of a non-infinite plate where heat extraction during the quench occurs in two dimensions near the edges. More complex yet is a block with similar dimensions in all three directions where heat extraction occurs three-dimensionally. It quickly becomes clear that very complex three-dimensional patterns of residual stresses develop in these less ideal geometries. This results in very difficult to predict distortions during subsequent machining.

The bottom line is, whenever possible, use starting material designed to keep residual stress patterns as simple as possible (and obviously as low as possible). Then use machining sequences that minimize upsetting or unbalancing these patterns. In situations where stress patterns must be disturbed, do this in a way that minimizes unbalancing of the stress pattern, specifically by machining incrementally from both sides, rather than taking large cuts from one side.

\section{COLD STRAIGHTENING}

Cold straightening is sometimes attempted before final machining to restore parts that have distorted during rough machining. This is rarely successful with large complex parts, such as satellite boxes. It is difficult to straighten distorted decks without also bending the adjacent webs, and visa versa. In addition, cold bending introduces highly asymmetric residual stresses into each straightened section. ${ }^{1}$ These stresses are particularly high near the surfaces. If these highly stressed surfaces are machined off, large amounts of additional distortion occur. ${ }^{1}$ As a result, cold straightening is not recommended.

\section{PRACTICAL GUIDELINES FOR DESIGNING AND PRODUCING SATELLITE BOXES}

Based on the principles described in the preceding sections, the following guidelines are recommended for designing and producing satellite boxes at various strength levels. These guidelines do not take into account any factors of safety relative to strength. However, it is important to recognize that repeated loading (such as the vibrational loads experienced during launch) can cause metal fatigue at cyclic stress levels considerably below yield strength. For this reason alone, a factor of safety must be considered during the design phase. 


\subsection{Boxes With Very Low Strength Requirements}

Consideration should be given to using annealed 5000-series aluminum alloys for boxes requiring yield strengths below $\sim 15 \mathrm{ksi}$. Such materials should be virtually free from residual stresses and machining distortion problems.

\subsection{Boxes With Intermediate Strength Requirements}

6061-T651 represents a good choice for boxes requiring yield strengths up to 35 ksi. The following sequence has been proven effective during recent production of several designs of varying complexity.

- Start with 6061-T651 plate (solution heat treated, quenched, mechanically stress leveled in tension, and aged) slightly thicker than the depth of the desired box. Commercially available 6061-T651 plates in thicknesses of 10 to 12 inches exhibit aged strengths that are 85 to 90\% of handbook values, i.e., 35 ksi yield. In addition, 6061 has inherently lower quench-induced residual stresses than 7075, and mechanical stress leveling will reduce these by an additional 80 to $95 \%$. The remaining peak residual stress magnitude should be less than $\sim 2 \mathrm{ksi}$.

- If an added margin of safety is essential, cut off the edges where stresses may be more complex and machining distortion less predictable.

- Design and orient the box so that pockets are machined with their long directions parallel to the thickness direction - this orientation minimizes disrupting and unbalancing the remaining pattern of residual stresses. Avoid designing in features that will result in substantial asymmetry relative to the mid-plane of the plate.

- Rough in the pockets and major features first. Most substantial distortions should occur during the roughing cuts, leaving enough overstock for detailed features and clean up to final dimensions. Then finish machine to final dimensions.

- In situations where residual stress patterns are likely to become unbalanced, machine incrementally from both sides, rather than taking large cuts from one side.

\subsection{Boxes Requiring High Strength}

If/when yield strengths higher than $~ 35$ ksi are needed, the higher-strength 7075 alloy must be used. Since 7075 cannot be effectively quenched in thick sections, the pockets must be roughed in before heat treatment, enabling an adequate quench rate to be obtained in the decks and webs.

- Rough-in the pockets leaving approximately 0.15 to 0.25 inch of overstock per side. This is most easily done with the material in the soft annealed condition, designated 7075-O.

- Solution heat treat the roughed box and quench it in $\sim 175$ to $180^{\circ} \mathrm{F}$ water. Using quench water in this temperature range results in an $\sim 80 \%$ reduction in residual stresses, while reducing aged strength by only $\sim 15 \%{ }^{1}$ The roughed box should enter the quench tank with all walls and decks perpendicular to the surface of the water - otherwise bending is likely to occur during the quench, and complex asymmetric residual stress patterns will develop in the walls and decks, making them much more prone to distortion during subsequent machining. 
- Following quenching, overage the roughed box to the T73 condition. This results in slightly less than peak strength, but accomplishes an additional 36\% of stress relief, and produces significantly better fracture toughness and resistance to stress corrosion cracking. The resulting yield strength should be in the vicinity of $55 \mathrm{ksi}$.

- Use intermediate machining steps to get the webs and decks close to final dimensions. Remember that the planes of the decks and webs are perpendicular to the direction of heat extraction direction during quenching of the roughed box, so the in-plane residual stresses in each deck and web will be compressive on the surfaces and tensile in the midplanes, potentially requiring incremental machining from both sides to avoid excessive bending distortion.

- Finish machine the decks and webs to final dimensions. 


\section{REFERENCES}

1. M. S. Younger and K. H. Eckelmeyer, Overcoming Residual Stresses and Machining Distortion In Age Hardened Aluminum Alloy Satellite Boxes, Sandia National Laboratories Report, 2007.

2. Metals Handbook, $10^{\text {th }}$ Edition, Volume 2, Properties \& Selection of Nonferrous Alloys and Special Purpose Materials, ASM International, 1990, pp. 3-122.

3. Metals Handbook, $10^{\text {th }}$ Edition, Volume 4, Heat Treating, ASM International, 1991, pp. 841-879.

4. J. F. Hatch, Aluminum: Properties and Physical Metallurgy, ASM International, 1984. 


\section{DISTRIBUTION}

$\begin{array}{lll}5 & \text { MS-0968 } & \text { M. Younger, 2622 } \\ 1 & \text { MS 0343 } & \text { J. Woodard, 2600d } \\ 1 & \text { MS 0343 } & \text { K. Lee, 2600 } \\ 1 & \text { MS 0343 } & \text { M. Gonzales, 2610 } \\ 1 & \text { MS 0343 } & \text { S. Castillo, 2600 } \\ 1 & \text { MS 0343 } & \text { S. Guthrie, 2600 } \\ 1 & \text { MS 0521 } & \text { E. Boucheron, 2617 } \\ 1 & \text { MS 0561 } & \text { D. Abrams, 24315 } \\ 1 & \text { MS 0561 } & \text { D. Reckaway, 24314 } \\ 1 & \text { MS 0886 } & \text { A. Kilgo, 1822 } \\ 1 & \text { MS 0965 } & \text { B. D. Boughton, 2611 } \\ 1 & \text { MS 0965 } & \text { M. A. Bernard, 2611 } \\ 1 & \text { MS 0968 } & \text { A. Routson, 2611 } \\ 1 & \text { MS 0968 } & \text { C. L. Gibson, 2611 } \\ 1 & \text { MS 0968 } & \text { D. J. Schmitt, 2611 } \\ 1 & \text { MS 0968 } & \text { J. D. Arvizu, 2611 } \\ 1 & \text { MS 0968 } & \text { J. L. Gonzales, 2611 } \\ 1 & \text { MS 0968 } & \text { J. P. Cresap, 2611, } \\ 1 & \text { MS 0968 } & \text { J. R. Callicoat, 2611 } \\ 5 & \text { MS 0968 } & \text { K. Eckelmeyer, 1822 } \\ 1 & \text { MS 0968 } & \text { K. S. Rawlinson, 2611 } \\ 1 & \text { MS 0968 } & \text { M. A. Tidwell, 2611 } \\ 1 & \text { MS 0968 } & \text { M. J. Tritt } \\ 1 & \text { MS 0968 } & \text { N. G. Rackley, 2611 } \\ 1 & \text { MS 0968 } & \text { R. J. Kipp, 2611 } \\ 1 & \text { MS 0968 } & \text { S. C. Dropinski, 2611 } \\ 1 & \text { MS 0968 } & \text { T. J. Dubay, 2611 } \\ 1 & \text { MS 0968 } & \text { W. M. McMurtry, 2611 } \\ 1 & \text { MS 4536 } & \text { Technical Library, 9536 (electronic copy) }\end{array}$


